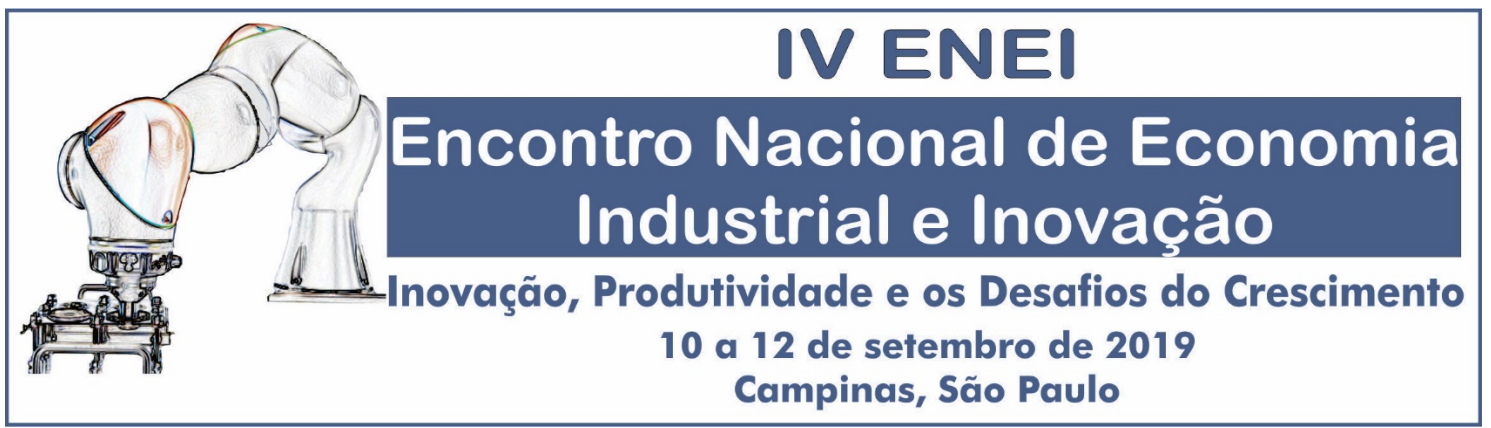

DIGITALIZAÇÃO FINANCEIRA: EFEITOS DO MOBILE E HOME BANKING SOBRE AS TARIFAS BANCÁRIAS BRASILEIRAS

\title{
Mateus Feld
}

Mestrando em Economia pela Universidade do Vale do Rio dos Sinos (PPGE/UNISINOS).

\section{Tatiana Silva Fontoura de Barcellos Giacobbo}

Doutoranda em Economia pela Universidade do Vale do Rio dos Sinos (PPGE/UNISINOS).

\section{Wagner Eduardo Schuster}

Mestrando em Economia pela Universidade do Vale do Rio dos Sinos (PPGE/UNISINOS).

Área Temática ENEI: 1.2 - Competição, preços e estruturas de mercado

\section{RESUMO}

Este trabalho tem como objetivo investigar o impacto que o uso do mobile e do home banking tiveram sobre as tarifas bancárias no Brasil entre 2011 e 2018. Inicialmente, apresenta-se uma evolução temporal do e-banking no Brasil. Em seguida, trata-se dos efeitos do e-banking sobre a concorrência, através do modelo de rede-cidade de Wang e Wang (2018), uma evolução dos modelos seminais de cidade linear de Hotteling (1929) e cidade circular de Salop (1979). Por fim, mostra-se o estudo empírico realizado, através do qual se conclui que as tarifas bancárias foram impactadas pelas plataformas digitais. Os resultados indicam que a diminuição dos custos de transporte, propiciada pela digitalização financeira, reduziu o preço das tarifas bancárias aos consumidores no período analisado.

PALAVRAS-CHAVE: Tarifas bancárias. Concentração bancária. E-banking. Modelo de localização rede-cidade.

Classificação JEL: C32, G21, L86.

\begin{abstract}
This paper aims to investigate the impacts of mobile and home banking use on bank fees in Brazil, from 2011 to 2017. Firstly, we present a brief evolution of e-banking in Brazil. Then, we discuss the effects of e-banking on competitiveness, through a network-city model developed by Wang-Wang (2018), which is an evolution of the seminal models of linear-city, developed by Hotteling (1929), and circular-city, developed by Salop (1979). Finally, we present our empirical study, through which we conclude that bank fees were impacted by the digital banking platforms. The results indicate that the decrease on transport costs, caused by the financial digitization, has reduced the price of bank fees to customers in the studied period.
\end{abstract}

KEY-WORDS: Bank fees. Bank concentration. E-banking. Network-city model. JEL classification: C32, G21, L86. 


\section{Introdução}

O objetivo deste artigo é analisar o impacto dos canais digitais de serviços financeiros (e-finance) sobre as tarifas bancárias cobradas dos consumidores no Brasil, a partir de uma análise empírica no período de 2011 a 2018. O estudo tem como base teórica o modelo de rede-cidade de Wang e Wang (2018), evolução dos modelos seminais de localização de Hotelling (1929) e Salop (1979), para mensurar o aspecto espacial da estrutura bancária brasileira.

A estrutura de mercado oligopolista permanece caracterizando o mercado bancário brasileiro, visto que as últimas décadas foram marcadas por privatizações e por grande número de fusões e aquisições (Hordones, 2019), apesar do recente surgimento de bancos totalmente digitais e da ampliação do número de empresas do tipo fintech (BARBOSA, 2018). Bittencourt et al. (2015) relatam que há anos as instituições do setor bancário brasileiro (na tendência mundial) vêm passando por processos de fusão - que se intensificaram com a crise financeira mundial de 2008 -, o que abre debate sobre os efeitos dentro da estabilidade financeira. De acordo com a Federação Brasileira de Bancos (Febraban, 2017), a razão de concentração (Concentration Ratio) das cinco maiores empresas (CR5) do setor bancário, pelo critério de receitas, no Brasil é de $82 \%$ - a maior entre os países emergentes, e o segundo maior do mundo, ficando apenas atrás da Holanda, cujo referido índice de concentração é de $89 \%$ (BACEN, 2018).

$\mathrm{O}$ ecossistema de startups de tecnologia financeira tem apresentado crescimento nos últimos anos - segundo dados da Febraban (2018), em novembro de 2017 haviam registrados 6 bancos digitais e 332 empresas iniciantes, que representa $36 \%$ de crescimento no período de 9 meses. Dessa forma, inicia-se uma discussão sobre os impactos destas empresas digitais na competitividade do setor. A digitalização deste modelo de negócios reduz custos marginais de operações e custos de troca, o que facilita a entrada de novas firmas (BACEN, 2018). O modelo de negócio eletrônico também é caracterizado por fortes vendas e crescimentos nos ganhos, ambos impulsionados por um ambiente inovativo, que os possibilita acelerar o desenvolvimento de novos projetos e investimentos para o mercado (DAPP, 2015; COETEZEE, 2018).

Diante desse contexto, a questão básica a ser respondida é se as tarifas bancárias foram impactadas pela instituição e ampliação das plataformas digitais (e-banking). Deseja-se verificar quais os fatores que mais impactam para a determinação das tarifas bancárias aplicadas pelos bancos brasileiros. Secundariamente, pretende-se inferir se, com a redução ou eliminação do fator localização na escolha do banco do cliente, advindas da digitalização financeira, houve redução nas tarifas bancárias praticadas pelos bancos. $\mathrm{O}$ argumento fundamental deste trabalho é o de que em decorrência de poucos bancos terem grande poder de mercado, as tarifas são definidas em conluio e o e-banking reduz o efeito localização e a assimetria informacional no mercado bancário, gerando pressões para que as tarifas sejam reduzidas.

\section{Evolução da digitalização bancária no Brasil}

A forma como a sociedade - indivíduos e empresas - lida com o seu dinheiro evolui constantemente, junto aos progressos tecnológicos alcançados nas últimas décadas. A história da moeda remonta há mais de 4.000 anos, inicia-se com o escambo, passa pela criação do papel-moeda, o surgimento dos primeiros cartões de crédito, na década de 1920 e somente nos anos 1990 surgem os acessos ao internet banking. (GALBRAITH, 1997).

A evolução tecnológica revolucionou o mercado financeiro e possibilitou aos bancos ofertar uma gama crescente de produtos e serviços automatizados aos seus clientes (VEIGA, 
OLIVEIRA, 2006). Partindo dos cartões de saque e caixas eletrônicos (em inglês Automated Teller Machine - ATM's), até a introdução da internet, dos Postos de Atendimento Eletrônico (PAE's) e dos bancos virtuais nas transações bancárias, a organização do setor, bem como a dinâmica de relacionamento entre os bancos e a sociedade, sofreu profundas transformações. Os investimentos e despesas dos bancos brasileiros em tecnologia atingiram R $\$ 19,6$ bilhões em 2018 - um crescimento de 3\% em relação ao ano anterior (FEBRABAN, 2019).

No Brasil, em 2018, os canais digitais já ocupavam 84\% das transações sem movimentação financeira e $23 \%$ das operações com transações financeiras, sendo que essas últimas tiveram um aumento de 5,2 bilhões em 2017 para 6,9 bilhões em 2018 (Febraban, 2019). Diante desse cenário, abre-se espaço para discussão sobre a relevância e o futuro das tradicionais agências bancárias. Além disso, em meio à nova realidade do mercado, não há como discutir a competição no setor bancário sem mencionar o surgimento e consolidação dos bancos digitais e fintechs no país, que segue uma tendência mundial.

Gráfico 1: Número de transações bancárias no Brasil de 2011 a 2018

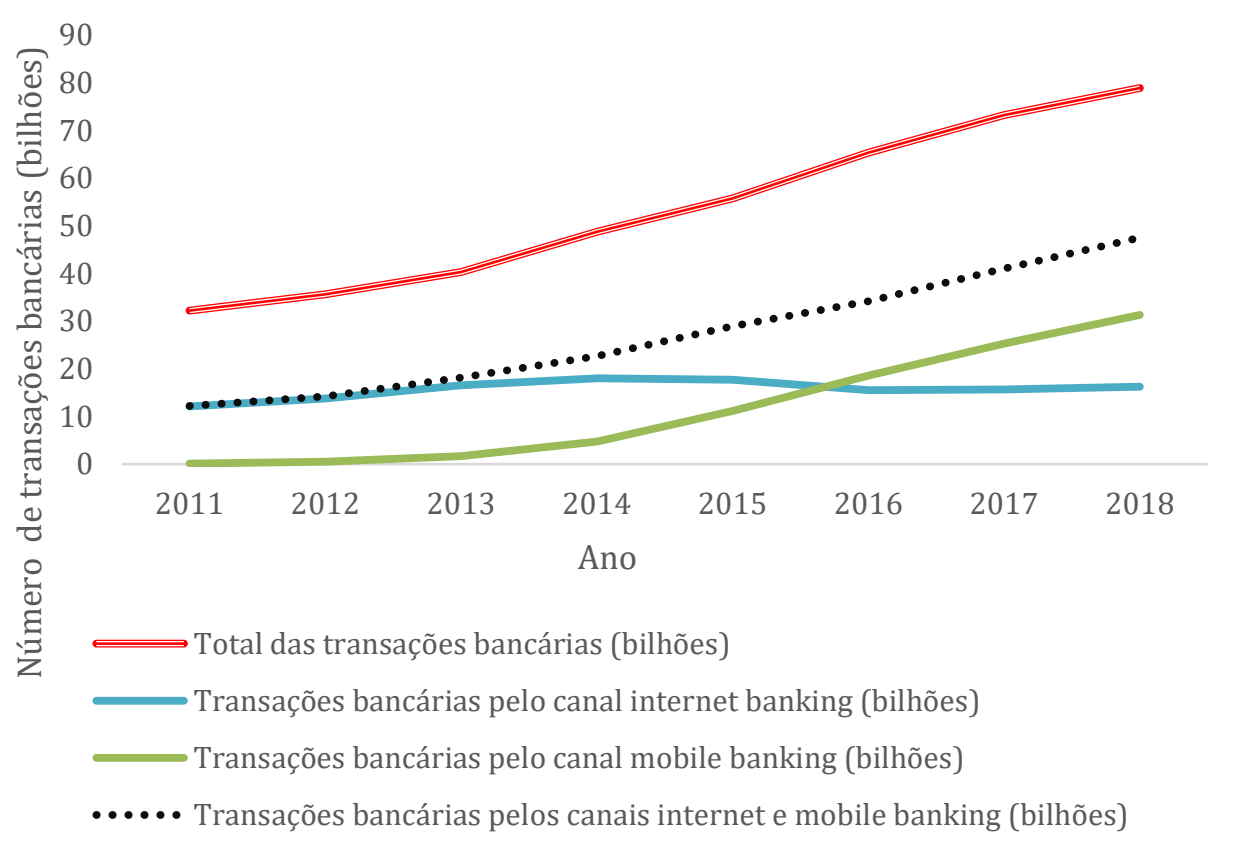

Fonte: elaboração própria, dados FEBRABAN (2019).

Conforme é possível verificar através do gráfico 1, o total das transações bancárias cresceu ano a ano, e da mesma forma, as transações feitas pelos canais digitais. É possível verificar, ainda, que em torno do ano de 2016 as transações feitas através de aplicativos mobile ultrapassaram as transações feitas através do internet banking no Brasil. Infere-se que tal fato seja consequência da ampliação da abrangência dos aparelhos de smartphones e tablets na sociedade. Somados, os dois canais representaram, em 2018, mais da metade das transações realizadas no Brasil: $60 \%$, sendo três pontos percentuais a mais do que o ano anterior.

\section{Efeitos do e-banking sobre a Concorrência}

Assim como no estudo de Veiga e Oliveira (2006), a análise realizada neste trabalho é baseada na definição do setor bancário brasileiro como um oligopólio, onde se verifica que os consumidores são capazes de perceber diferenças entre os produtos de diferentes firmas - ou 
seja, há diferenciação de produtos e, consequentemente, as firmas possuem poder de mercado.

Com os avanços tecnológicos que levaram à popularização do mobile e do internet banking, a competitividade do setor bancário tornou-se mais acirrada. As informações sobre os produtos, serviços, custos e benefícios de cada banco estão mais acessíveis, o que aumenta a gama de informações possuídas pelo consumidor no momento de optar por um banco.

Frente a esta evolução, discussões sobre a organização setorial são trazidas à tona. A maior parte da literatura existente sobre a economia brasileira tende a concluir que o setor bancário é competitivo, apesar dos altos níveis de concentração existentes (LUCINDA, 2010; ARAÚJO, JORGE NETO e PONCE, 2006; ARAÚJO e JORGE NETO, 2007; NAKANE, 2002). O Banco Central (REB, 2017), a partir dos indicadores de Lerner e Boone, conclui que houve tendência de aumento no grau de concorrência no setor bancário entre 2000 e 2016. A discussão é fomentada com os estudos de Tabak, Gomes e Medeiros Jr. (2015), Barbosa et al. (2015) e Divino e Silva (2017), que encontram evidências de que o setor bancário pode não ser competitivo.

Percebe-se que a literatura sobre os níveis de competitividade no setor bancário brasileiro apresenta divergências nos resultados entre os diferentes estudos. Entretanto, há um consenso de que o surgimento de inovações tecnológicas tem exigido, das instituições financeiras, mudanças em suas estratégias e formas de prestação de serviço - além de contribuir para um cenário mais dinâmico e competitivo (BITTENCOURT et al.,2015; GOMES, OLIVEIRA e MATIAS, 2017; COETEZEE, 2018). A maneira como os bancos capitalizam as novas oportunidades dos avanços tecnológicos - e lidam com as potenciais ameaças por elas proporcionadas - será fundamental para sua sobrevivência no ambiente competitivo do futuro (COETEZEE, 2018).

Neste sentido, o presente estudo procura entender os impactos da disseminação dos meios digitais de transação nos preços das tarifas bancárias. Vê-se duas frentes de possíveis efeitos: os pesados investimentos no desenvolvimento de novas tecnologias (pesquisa, desenvolvimento, aplicativos, medidas de segurança) podem impactar negativamente nos lucros das instituições financeiras, gerando um repasse de custos ao consumidor, o que levaria a um aumento da tarifa.

Em contraste, há a ideia de que estes investimentos possibilitam a redução de gastos operacionais com agências físicas, infraestrutura e número de funcionários - o que possibilitaria aos bancos o repasse dessa economia aos consumidores, através da redução das tarifas, em busca de maior competitividade. Além disso, a disseminação dos serviços remotos causaria uma diminuição do fator de diferenciação horizontal (locacional) entre os bancos, tornando-os mais homogêneos, o que também pode contribuir para a redução das tarifas (DEGRYSE, 1996; VEIGA E OLIVEIRA, 2006).

Inicialmente, com a finalidade de mostrar os efeitos que o e-finance pode ter sobre a concorrência, utilizar-se-á um modelo de competição espacial baseado em oligopólio de Bertrand, chamado de rede-cidade (livre tradução de network-city), desenvolvido por Wang e Wang (2018). Tal modelo pode ser usado para analisar várias questões relacionadas à organização industrial dos setores, como balanços, diversificação e fusões. A Tabela 1 abaixo fornece uma breve revisão da literatura sobre essa abordagem de competição por localização. 
Tabela 1: Evolução da Literatura nos modelos de competição por localização

\begin{tabular}{lcl}
\hline Autor & Período & \multicolumn{1}{c}{ Modelo } \\
\hline Hotteling & 1929 & Cidade linear \\
Salop & 1979 & Cidade circular \\
Von Ungern & 1991 & Multidimensional \\
Chen and Riordan & 2007 & Modelo de raios \\
Somaini and Einax & 2013 & Espacial dinâmico \\
Wang and Wang & 2018 & Rede-cidade \\
\hline
\end{tabular}

Fonte: Elaboração própria.

Muitos estudos mostram que a localização é um fator impactante na decisão de escolha do consumidor. Ao longo dos anos, o avanço dos meios de transporte e da tecnologia permitiu que o impacto da localização fosse se alterando. No modelo de Wang e Wang (2018), que utilizou-se neste artigo, por ser o mais contemporâneo e por considerarmos o mais condizente com a realidade, as firmas estão localizadas nos vértices da rede e competem com todas as outras direta e simultaneamente, enquanto os consumidores estão localizados ao longo dos elos que conectam os vértices e sofrem a ocorrência de custos de transporte quando decidem comprar de uma determinada firma.

Figura 1 - Modelo de Rede-Cidade

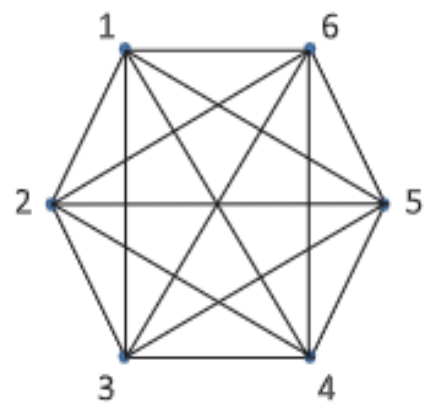

Fonte: Wang e Wang (2018).

Como se pode verificar através da ilustração da Figura 1, existe um número de $n$ firmas localizada nos vértices de uma rede de $n$-vértices (na ilustração são 6), com uma firma por vértice. Cada vértice é conectado ao outro por um elo de comprimento 1. Sendo assim, existe um total de $n(n-1) / 2$ elos. Os consumidores são uniformemente distribuídos, com a densidade em cada elo dada por $f$.

A firma $i$ tem um custo marginal constante de produção de $c_{i}$, e define o preço $p_{i}$, sendo que $i=1,2, \ldots, n$. Cada consumidor demanda 0 ou 1 unidade do produto, com 
disposição a pagar definida como $v$, e custos de transporte por unidade de distância denotado como $t$. O custo de transporte, assim como em Veiga e Oliveira (2006), deve ser considerado como uma desutilidade ao consumidor e pode ser interpretado como:

- o custo de troca de instituição, no sentido de que geralmente só é possível encerrar a abrir contas bancárias pessoalmente;

- o custo de ir até uma agência bancária realizar uma operação financeira em que a presença física seja obrigatória, como saque de grandes quantias de dinheiro.

A demanda pelo produto da firma $j$ é originada dos $n-1$ elos conectados à firma $j$. Assumindo o modelo de Wang e Wang (2018), tem-se que o preço é definido por:

$$
p_{j}=t+\frac{1}{2 n-1}\left(\sum_{i=1}^{n} c_{i}+(n-1) c_{j}\right)
$$

Desta forma, o preço de equilíbrio (tarifa) neste modelo será maior quanto maior forem os custos de transporte e os custos marginais, e menor for o número de bancos. Os custos dos bancos incorporam diversas variáveis, dentre as quais, destacam-se as despesas operacionais e administrativas bancárias, que serão exploradas no modelo empírico aplicado da seção 4.

Apesar de ser um modelo de localização mais complexo, sua aplicação no setor bancário é semelhante àquela encontrada no modelo de cidade circular de Salop (1979), porém incorpora as múltiplas relações de localização que a digitalização propiciou.

\section{Análise Empírica}

Tendo em vista o exposto, esta seção fará uma análise empírica dos efeitos do $e$ banking sobre as tarifas bancárias no período entre 2011 a 2018. Adotou-se a hipótese de que o preço das tarifas sofrerá efeito positivo dos custos de transporte e das despesas administrativas e efeito negativo do número de bancos, ou seja, as tarifas bancárias serão maiores quanto maior for o custo de transporte e as despesas administrativas e serão menores quanto maior for o número de bancos (menor concentração do setor). $\mathrm{O}$ número de transações por mobile e home banking foi utilizado como variável inversa ao custo de transporte, já que o uso destas tecnologias gera uma comodidade aos consumidores e diminui a diferenciação horizontal (locacional) do setor bancário.

Para esta análise, foram utilizados dados das seguintes fontes: Banco Central do Brasil, que reúne informações sobre todas as instituições financeiras autorizadas a operar no país; base de dados da Fundação Getúlio Vargas (FGV), para obtenção das séries do Índice Geral de Preços Mercado (IGP-M), utilizado para deflacionar as séries do modelo; e os relatórios publicados pela Federação Brasileira de Bancos (FEBRABAN), que apresentam informações relativas à utilização de mobile e home (ou internet) banking no Brasil.

Quanto aos dados obtidos do Banco Central (BACEN), mais especificamente, cabe frisar que se utilizou o "Balancete / Balanço Geral", o qual contém as informações que as instituições financeiras são obrigadas a enviar mensalmente ao BACEN. Dentre as contas consultadas, destacamos as de código "71700009" e "81700006" que são, respectivamente, as contas de "Rendas de Prestação de Serviços" e "Despesas Administrativas". Além disso, empregaram-se, também, os dados referentes ao Fundo Garantidor de Crédito (FGC), que trazem informações sobre o total de clientes com contas no Brasil. As variáveis utilizadas são mensais, compreendendo o período entre janeiro de 2011 e dezembro de 2018, totalizando 96 observações.

O modelo econométrico realizado segue o seguinte formato: 
Conforme abordado na seção 3, espera-se que todas as variáveis tenham efeito positivo sobre o a variável dependente TARIFA (que representa o valor das tarifas cobradas dos consumidores). Assim, quanto maiores forem as variáveis independentes - despesas dos bancos, o custo de transporte e o nível de concentração -, maior será o preço médio das tarifas cobradas.

Para criação da variável TARIFA, utilizaram-se os valores contidos na conta "71700009" do Banco Central, que são as "Receitas de Prestação de Serviços" 1. Para o cálculo desta variável, utilizou-se a soma mensal do total de receitas de prestação de serviços, para todas as Instituições Financeiras ${ }^{2}$. Essa variável foi deflacionada pelo IGP-M e dividida pelo número de contas correntes ativas no $\mathrm{mês}^{3}$, como forma de calcular uma receita média por conta corrente.

Sendo assim, a fórmula para o cálculo da variável TARIFA é a que segue:

$$
\text { TARIF } A_{j}=\frac{\sum_{i=1}^{n} \text { Rendas de outros serviços no mês }}{j, i}
$$

O Gráfico 2 apresenta a evolução do valor da variável TARIFA ao longo do período analisado. O preço médio de tarifas de toda a amostra é de $\mathrm{R} \$ 33,27$, porém percebe-se que há bastante volatilidade nesse valor, com uma possível sazonalidade. Contudo, ao longo do período, há uma tendência de queda no valor das tarifas bancárias.

Gráfico 2: Tarifas bancárias de 2011 a 2018

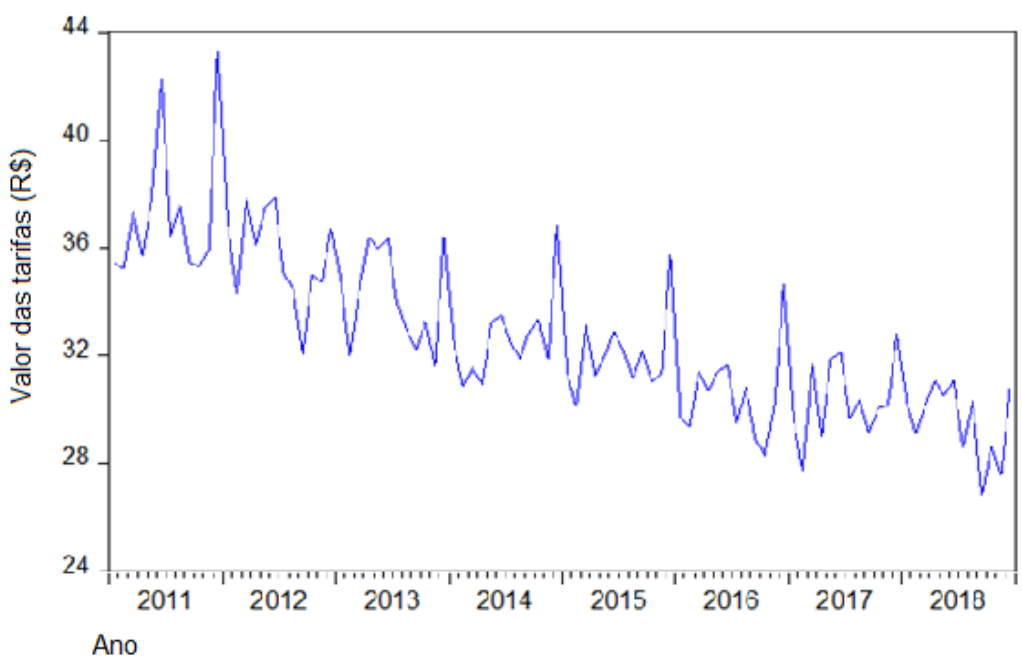

Fonte: Elaboração própria.

Para a variável DESPESAS, utilizaram-se os valores contidos na conta "81700006", que representa as "despesas administrativas" dos bancos. É nesta conta que as instituições financeiras registram despesas como custos com funcionários e aluguéis. Empregou-se o total

\footnotetext{
${ }^{1}$ É nesta conta que as Instituições Financeiras registram diversas de suas receitas, entre elas, as provenientes de tarifas bancárias. Seria mais assertivo se fosse possível segregar apenas as receitas que efetivamente se originam das tarifas, porém, este dado não está disponível de maneira isolada.

2 Esta variável é informada de maneira cumulativa ao semestre, portanto, para chegar-se ao valor mensal foram subtraídos os valores dos meses subsequentes dentro de cada semestre.

${ }^{3}$ É importante salientar que os dados referentes ao número de contas correntes são apenas disponibilizados de maneira semestral e, portanto, seus valores semestrais foram replicados para todos os meses que fazem parte daquele devido semestre.
} 
de receitas de prestação de serviços somado de forma mensal para todas as instituições financeiras ${ }^{4}$. Estes valores foram deflacionados pelo IGP-M e aplicados em forma de bilhões.

O Gráfico 3 mostra a evolução das despesas no período estudado. As despesas dos bancos têm um comportamento bastante volátil e sem uma tendência previsível, embora haja também uma possível sazonalidade nos finais de ano.

Gráfico 3: Despesas totais dos bancos

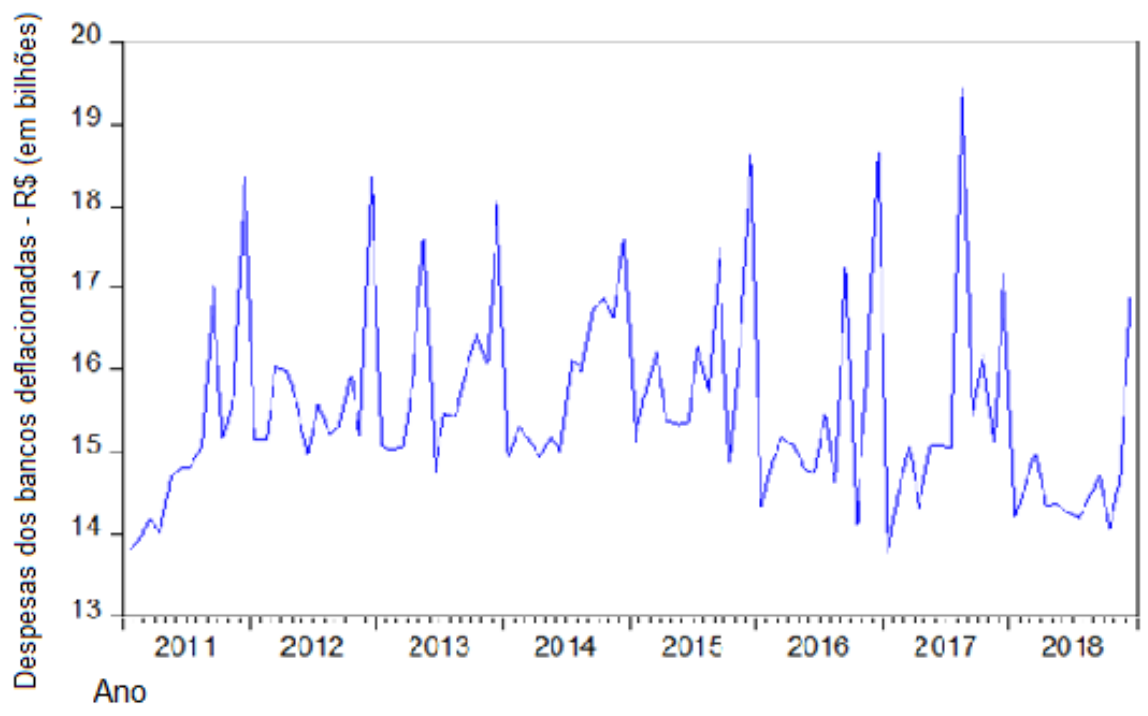

Fonte: Elaboração própria.

Com relação a variável representativa do CUSTO DE TRANSPORTE, utilizou-se o número total de movimentações bancárias (em bilhões) realizadas nas modalidades de mobile e home banking como proxy representativa do inverso do custo de transporte, e a variável foi chamada de MOBILE_INTERNET. A ideia é que o cliente, ao realizar suas transações via mobile ou home banking não precisa se deslocar até sua instituição bancária, ou seja, neste caso a utilização destes meios serve como o inverso de um custo de transporte para o cliente. Metodologia semelhante é aplicada por Veiga e Oliveira (2006), entretanto, como já explicado anteriormente, os autores utilizam o número de PAE's como variável representativa do inverso do custo de transporte.

Em sua pesquisa de tecnologia bancária, a FEBRABAN disponibiliza os volumes transacionados em cada modalidade (agências, ATM, Home, Mobile) com e sem movimentação financeira. Sendo assim, foram utilizadas as somas das utilizações ano a ano das transações com e sem movimentação financeira nas modalidades mobile e home banking, e estes valores foram convertidos em dados mensais ${ }^{5}$ para formação da variável. O quadro 1 apresenta a evolução da utilização consolidada anual das modalidades mobile e home banking no Brasil, para transações com e sem movimentação financeira. Nota-se um crescimento destas modalidades ao longo do tempo, o que já era esperado, dada a disseminação do uso da internet e de smartphones visto na sociedade, bem como dos fortes investimentos por parte dos bancos em novas tecnologias que facilitem o acesso dos consumidores aos seus produtos.

\footnotetext{
${ }^{4}$ Esta variável também é informada de maneira cumulativa ao semestre, portanto para chegar-se ao valor mensal foram subtraídos os valores dos meses subsequentes dentro de cada semestre.

${ }^{5}$ Como as informações são disponibilizadas de maneira anual, utilizou-se seu crescimento médio mensal para simular os valores de utilizações em cada mês, de forma que estes valores mensais evoluíssem na mesma proporção do crescimento anual e sua soma, no ano, fosse igual ao número de utilizações no ano disponibilizadas pela FEBRABAN.
} 
Quadro 1: Utilização de internet banking e mobile banking (bilhões de transações)

\begin{tabular}{|c|c|c|c|}
\hline Ano & Home & Mobile & TOTAL \\
\hline 2011 & 12,1 & 0,1 & 12,2 \\
\hline 2012 & 13,7 & 0,5 & 14,2 \\
\hline 2013 & 16,5 & 1,6 & 18,1 \\
\hline 2014 & 18 & 4,7 & 22,7 \\
\hline 2015 & 17,7 & 11,2 & 28,9 \\
\hline 2016 & 15,5 & 18,6 & 34,1 \\
\hline 2017 & 15,7 & 25,3 & 41 \\
\hline 2018 & 16,2 & 31,3 & 47,5 \\
\hline
\end{tabular}

Fonte: Elaboração própria.

Para a variável correspondente a CONCENTRAÇÃO, utilizou-se o índice de Hirshman-Herfindahl (HHI) que é definido pela soma dos quadrados das participações de mercado dos bancos. O índice HHI é a principal medida utilizada por reguladores para medir o grau de concentração de um mercado (Hordones, 2019) e é bastante disseminado na literatura da área de Organização Industrial. A equação que resulta no $\mathrm{HHI}^{6}$ é a seguinte:

$$
H H I_{j}=\sum_{i=1}^{m}\left(\frac{X_{i, j}}{X_{j}}\right)^{2} \cdot 10000
$$

onde $X i, j$ representa a receita proveniente de tarifas para a instituição $i$ no período $j$, e $X j$ representa a soma das receitas para todas as instituições da amostra no período $j$. Este índice pode ser calculado com base em diversas rubricas, como o número de contas por cada instituição, o número de clientes, as receitas totais, entre outros. Neste trabalho optou-se por calculá-lo com base nas receitas provenientes de tarifas.

Antes da análise dos resultados encontrados para as variáveis, alguns testes são necessários. Primeiramente, por tratar-se de uma série de tempo, as variáveis devem ser estacionárias. Para tanto, realizou-se o teste Dickey-Fuller Aumentado. Obteve-se como resultado, conforme o Quadro 2, que as variáveis TARIFA - variável dependente do modelo - e MOBILE_INTERNET não são estacionárias.

Quadro 2: Estacionariedade das Variáveis

\begin{tabular}{|l|l|l|l|l|}
\hline VARIÁVEL & ESTADO & ADF & P-VALUE & RESULTADO \\
\hline TARIFA & Nível & -1.683484 & 0.4359 & Não Estacionária \\
\hline DESPESA_BI & Nível & -8.834456 & 0.0000 & Estacionária \\
\hline HHI & Nível & -6.400460 & 0.0000 & Estacionária \\
\hline MOBILE_INTERNET & Nível & 4.716077 & 1.0000 & Não Estacionária \\
\hline
\end{tabular}

Fonte: Elaboração própria.

\footnotetext{
${ }^{6} \mathrm{O}$ gráfico do índice HHI calculado está apresentado no apêndice.
} 
Testando estas variáveis em sua primeira diferença, chega-se à conclusão, conforme Quadro 3 a seguir, que as variáveis TARIFA e MOBILE_INTERNET são I(1), ou seja, integradas de ordem 1, pois são estacionárias em sua primeira diferença. Por sua vez, as variáveis DESPESA_BI e HHI são $I(0)$, já que são estacionárias em nível.

Quadro 3: Estacionariedade das Variáveis - primeira diferença.

\begin{tabular}{|l|l|l|l|l|}
\hline VARIÁVEL & ESTADO & ADF & P-VALUE & RESULTADO \\
\hline TARIFA & $1^{\text {a }}$ Diferença & -6.075772 & 0.0000 & Estacionária \\
\hline MOBILE_INTERNET & $1^{\text {a }}$ Diferença & -7.740546 & 0.0000 & Estacionária \\
\hline
\end{tabular}

Fonte: Elaboração própria.

Dado que as variáveis TARFIA e MOBILE_INTERNET são I(1), é necessário que as variáveis sejam cointegradas, visando a eliminar o risco de uma regressão espúria. Dizer que duas ou mais variáveis são cointegradas significa que elas possuem uma relação de longo prazo e, caso comprovada a cointegração, a metodologia de regressão tradicional (incluindo os testes t e F) é válida e a regressão não será espúria (GUJARATI; PORTER, 2011).

Se uma série, mesmo sendo obtida através de variáveis não estacionárias, gerar um resíduo estacionário, entende-se que esta série é cointegrada. Desta maneira, aplicando-se ao resíduo o mesmo teste de estacionariedade ADF feito sobre as variáveis do modelo, chegouse a um valor t de -4.426202 e, portanto, é possível afirmar, a um nível de 5\% de significância, que o resíduo é estacionário. Além deste teste, foi realizado também o teste de cointegração de Johansen que, conforme tabela 2, possibilita aceitar a hipótese de que, ao menos 2 ou 3 variáveis são cointegradas.

Tabela 2: Teste de cointegração de Johansen

\begin{tabular}{lcccc}
\hline \hline $\begin{array}{c}\text { Hypothesized } \\
\text { No. of CE(s) }\end{array}$ & Eigenvalue & $\begin{array}{c}\text { Trace } \\
\text { Statistic }\end{array}$ & $\begin{array}{c}\text { Valor Crítico a 5\% } \\
\text { de significância }\end{array}$ & Prob** \\
\hline \hline None * & 0.332870 & 80.42420 & 54.07904 & 0.0000 \\
\hline At most 1 * & 0.270408 & 43.59006 & 35.19275 & 0.0050 \\
\hline At most 2 & 0.102804 & 14.90050 & 20.26184 & 0.2321 \\
\hline At most 3 & 0.053762 & 5.028747 & 9.164546 & 0.2803 \\
\hline \hline *Denota rejeição da hipótese nula de que não há cointegração, a 5\% de significância & \\
**P-Valores de MacKinnon-Haug-Michelis (1999) & & \\
Fonte: Elaboração própria.
\end{tabular}

Depois de confirmada a cointegração da série, realizaram-se os testes de heterocedasticidade e autocorrelação serial sobre os resíduos. Com relação à heterocedasticidade, utilizou-se o teste de White que, conforme Tabela 3, indica que o modelo apresenta heterocedasticidade, dado que nenhuma das estatísticas permite aceitar a hipótese nula de que os resíduos são homocedásticos. 
Tabela 3 - Teste de White

Teste de Heterocedasticidade: White

\begin{tabular}{ll|ll}
\hline \hline F-statistic & 2.645 .028 & Prob. F(9,86) & 0.0094 \\
\hline Obs*R-squared & 2.081 .234 & Prob. Chi-Square(9) & 0.0135 \\
\hline Scaled explained SS & 3.278 .256 & Prob. Chi-Square(9) & 0.0001 \\
\hline
\end{tabular}

Fonte: elaboração própria.

Quanto à autocorrelação dos resíduos, o valor $d$ de Durbin-Watson foi de 1.318997 e já indica a presença de autocorrelação nos resíduos, uma vez que, para uma amostra de 96 observações e com 3 variáveis dependentes, o valor encontrado está abaixo da banda máxima. Além disso, realizou-se o teste de Breusch-Godfrey, conhecido como teste LM, que indicou, a um nível de 5\% de significância, a presença de autocorrelação nos resíduos, confirmando o resultado o resultado do teste de Durbin-Watson.

Como visto, o modelo apresentou autocorrelação e heterocedasticidade nos resíduos. Sendo assim, os resultados encontrados podem estar viesados. Para corrigir estes problemas, Gujarati e Porter (2011) sugerem que deve ser feita a correção do erro-padrão do modelo através dos erros padrão consistentes para heterocedasticidade e autocorrelação (CHA, ou HCA na sigla em inglês), conhecidos também como erros padrão de Newey-West. Esse procedimento corrige o erro-padrão para a presença de heterocedasticidade, como também o faz para a presença de autocorrelação, possibilitando a correção das questões residuais apresentadas no modelo proposto.

Aplicados os ajustes necessários, obtiveram-se os resultados através de uma regressão linear robusta estimada pelo método de Mínimos Quadrados Ordinários (MQO). Os resultados ajustados são apresentados a seguir:

Tabela 4 - Resultados da regressão com modelo ajustado

\begin{tabular}{|c|c|c|c|c|}
\hline Variável & Coeficiente & Desvio Padrão & Estatística t & P-Valor \\
\hline $\mathrm{C}$ & 4.869 .084 & 7.922 .736 & 6.145 .711 & 0.0000 \\
\hline DESPESA_BI & 0.429994 & 0.210246 & 2.045 .190 & 0.0437 \\
\hline HHI & -0.013325 & 0.004189 & -3.181 .261 & 0.0020 \\
\hline MOBILE_INTERNET & -1.984 .590 & 0.242379 & -8.187 .965 & 0.0000 \\
\hline $\mathbf{R}^{2}$ & 0.684508 & \multicolumn{2}{|c|}{ Média da variável dependente } & 3.281 .377 \\
\hline $\mathbf{R}^{2}$ Ajustado & 0.674220 & \multicolumn{2}{|c|}{$\begin{array}{l}\text { Desvio Padrão da variável } \\
\text { dependente }\end{array}$} & 3.103 .488 \\
\hline Erro padrão da regressão & 1.771 .382 & \multicolumn{2}{|l|}{ Critério Akaike } & 4.022 .171 \\
\hline SQR & 2.886 .770 & \multicolumn{2}{|c|}{ Critério Schwarz } & 4.129 .018 \\
\hline Log likelihood & -1.890 .642 & \multicolumn{2}{|c|}{ Critério Hannan-Quinn } & 4.065 .360 \\
\hline Estatística F & 6.653 .602 & \multicolumn{2}{|c|}{ Estatística Durbin-Watson } & 1.318 .997 \\
\hline Prob(F-statistic) & 0.000000 & \multicolumn{2}{|c|}{ Estatística de Wald-F } & 3.249 .338 \\
\hline Prob(Wald F-statistic) & 0.000000 & & & \\
\hline
\end{tabular}

Fonte: Elaboração própria.

Primeiramente, nota-se que todas as variáveis apresentaram significância estatística, uma vez que o teste " $t$ ", individualmente, nos permite rejeitar a hipótese nula de que os coeficientes são estatisticamente iguais a zero. Além disso, o teste " $F$ ", ao apresentar o valor 
de 60,53602, também nos permite afirmar que todas as variáveis independentes, em conjunto, são significantes estatisticamente.

Quanto aos valores dos coeficientes, nota-se que a variável DESPESA_BI possui sinal positivo, ou seja, um aumento nas despesas das instituições financeiras implica em um crescimento nos preços das tarifas, resultado que já era esperado.

A variável HHI, apesar de estatisticamente significante, apresentou resultado diferente do esperado. A expectativa seria de um sinal positivo, no sentido de que o aumento da concentração implicaria em maior poder de mercado por parte das maiores instituições financeiras do país, o que, consequentemente, implicaria em um aumento das tarifas. Entretanto, o sinal negativo nos mostra que a concentração teve um impacto negativo nas tarifas para o período analisado.

Por fim, a variável MOBILE_INTERNET apresentou um sinal negativo, evidenciando que a disseminação das movimentações via mobile e home banking implicou em uma redução no valor das tarifas bancárias para o período avaliado. De acordo com o coeficiente calculado, um aumento de um bilhão no número de movimentações via mobile ou home banking (com ou sem transação financeira), implica, na média, em uma redução de $\mathrm{R} \$$ 1,98 real nos custos das tarifas bancárias. Além do mais, o valor do $\mathrm{R}^{2}$ ajustado foi de 0,67422, ou seja: as variáveis independentes são capazes de explicar, em conjunto, $67,42 \%$ da variável TARIFA, o que mostra que o modelo está bem ajustado.

É importante ressaltar que os resultados encontrados levaram em consideração a existência de cointegração entre, pelo menos, 2 ou 3 variáveis do modelo. Deste modo, ao dizer que a série é cointegrada, afirma-se que existe uma relação de longo prazo entre os dados. Cabe ressaltar, porém, que no curto prazo o comportamento entre as variáveis pode se dar de forma diferente. Para analisar os resultados no curto prazo, um dos métodos disponíveis seria aplicar o Mecanismo de Correção de Erros (MCE), o que se optou por não fazer, já que o foco deste trabalho recai sobre uma análise de longo prazo. Destaca-se, dessa forma, que a relação encontrada na regressão é de longo prazo. Assim, deixa-se como uma sugestão para pesquisas futuras a análise do comportamento destas variáveis no curto prazo.

\section{CONCLUSÕES}

O setor bancário brasileiro sofreu mudanças estruturais nas últimas duas décadas, provenientes, principalmente, dos avanços tecnológicos conquistados no setor. Como visto, os investimentos e despesas em tecnologia tem tido crescimento, o que salienta a importância que a modernização e o desenvolvimento de novas soluções têm para o setor.

$\mathrm{O}$ aumento da oferta de serviços bancários através da internet (e-banking), revolucionou a dinâmica do setor, tornando o relacionamento entre consumidores e instituições financeiras mais ágil, automatizado, eficiente e democrático. Além disso, o ebanking reduz a assimetria de informação existente entre as partes, bem como os custos de transporte incorridos pelos consumidores na busca pelos serviços bancários.

Este trabalho buscou investigar, através de um estudo econométrico, os impactos que a disseminação do mobile banking e do home banking tiveram sobre as tarifas bancárias ao longo do período analisado, que compreende os anos de 2011 a 2018. Adotou-se a hipótese de que o preço das tarifas deveria ser tão maior quanto maior fossem os custos de transporte e as despesas administrativas, e menor fosse o número de bancos (maior concentração do setor). $\mathrm{O}$ número de transações por mobile e home banking foi utilizado como variável inversa ao custo de transporte, já que o uso destas tecnologias gera uma comodidade aos consumidores e diminui a diferenciação horizontal (locacional) do setor bancário.

O principal resultado encontrado é a evidência de que, ao longo do período avaliado, o crescimento no número de movimentações bancárias via mobile e home banking 
proporcionou um impacto negativo no valor das tarifas cobradas pelos bancos. Ou seja, uma redução dos custos de transporte - proporcionada pela disseminação do e-banking - gerou uma queda nas tarifas bancárias. Além disso, há evidências de que as despesas dos bancos estão positivamente relacionadas com o valor cobrado em suas tarifas. Esses resultados confirmam o esperado segundo a hipótese adotada de que o preço das tarifas deveria ser tão maior quanto maior fossem os custos de transporte e as despesas administrativas.

É interessante notar que o sinal negativo da variável TARIFAS mostra que o efeito da disseminação do e-banking (redução do custo de transporte) predominou sobre o efeito do aumento das despesas. Ou seja, ainda que as despesas estivessem crescendo, a pressão gerada pela redução dos custos de transporte possibilitou uma redução no preço das tarifas. Todos os resultados encontrados mostraram-se estatisticamente significativos, porém, apesar de terem sido encontrados os resultados esperados para os efeitos do e-banking e das despesas, $\mathrm{o}$ mesmo não aconteceu para o número de bancos e o índice de concentração (HHI).

Trabalhos semelhantes, como o de Veiga e Oliveira (2006), foram conduzidos para períodos anteriores. Contudo, como o mobile e o home banking não eram tecnologias disseminadas na época, os autores mensuraram a digitalização através da quantidade de Postos de Atendimento Eletrônico (PAE). O resultado encontrado neste trabalho quanto ao uso do mobile e home banking foi semelhante ao dos autores citados, o que demonstra que o progresso tecnológico tem cada vez mais poder de impactar nas condições de competição do setor.

Por fim, cabe salientar que, além dos ganhos de praticidade, eficiência e tempo proporcionados pela disseminação do mobile banking e do home banking, essas tecnologias também contribuíram para uma redução nas despesas dos clientes que pagam tarifas bancárias. Esse é um resultado interessante, pois mostra o potencial que o desenvolvimento de novas tecnologias tem de impactar um setor oligopolizado, competitivo e que oferece serviços e produtos relativamente homogêneos. A redução nas tarifas é benéfica aos consumidores e estimula a competição entre os grandes players do setor, ao passo que abre espaço para novas instituições financeiras com grande foco em tecnologia, como as fintechs.

\section{Referências bibliográficas}

ARAÚJO, L. A. D. D.; JORGE NETO, P. D. M.; PONCE, D. A. S. Competição e Concentração entre os Bancos Brasileiros. Revista Economia, v.7, n.3, p.561-586, 2006.

ARAÚJO, L. A. D. D; JORGE NETO, P. D. M. Risco e competição bancária no Brasil. Revista Brasileira de Economia, v. 61, n. 2, p. 175-200, 2007.

BANCO CENTRAL DO BRASIL, BACEN. Relatório de Economia Bancária 2017. 2018.

BANCO CENTRAL DO BRASIL. Balancetes e Balanços Patrimoniais. Disponível em: $<$ https://www.bcb.gov.br/estabilidadefinanceira/balancetesbalancospatrimoniais $>$. Acesso em: 09 fev. 2019.

BANCO CENTRAL DO BRASIL. Estatísticas censo semestral sobre os créditos garantidos pelo FGC. Disponível em: <https://www.bcb.gov.br/estatisticas/fgccensosemestral $>$ Acesso em: 12 fev. 2019.

BARBOSA, K.; ROCHA, B. P.; SALAZAR, F. Assessing competition in the banking industry: a multi-product approach. Journal of Banking and Finance, v. 50, p. 340-62, 2015. 
BARBOSA, Roberto Rodrigues. Fintechs: a atuação das empresas de tecnologia de serviço financeiro no setor bancário e financeiro brasileiro. 2018. Dissertação de Mestrado.

BECK, T.; KUNT, A. D.; LEVINE, R. Bank concentration, competition, and crises: first results. Journal of Banking \& Finance, v. 30, p. 1581-1603, 2006.

BIKKER, Jacob A.; HAAF, Katharina. Measures of competition and concentration in the banking industry: a review of the literature. Economic \& Financial Modelling, v. 9, n. 2, p. 53-98, 2002.

BITTENCOURT, Wanderson Rocha et al. Estudo sobre a evolução da concentração do setor bancário no Brasil e da taxa de juros. Gestão, Finanças e Contabilidade, UNEB, Salvador, v. 5, n. 3, p. 05-25, maio/ago., 2015.

BUSCAROLLI, B; EMERICK, J. Econometria com Eviews. 1 ed. São Paulo: Saint Paul Editora LTDA, 2011.

CHEN, Yongmin; RIORDAN, Michael H. Price and variety in the spokes model. The Economic Journal, v. 117, n. 522, p. 897-921, 2007.

COETZEE, Johan. Strategic implications of Fintech on South African retail banks. South African Journal of Economic and Management Sciences. 21(1), a2455. DOI: https://doi.org/10.4102/sajems.v21i1.2455.

CRUZ, Pedro et al. Mobile banking rollout in emerging markets: evidence from Brazil. International Journal of bank marketing, v. 28, n. 5, p. 342-371, 2010.

DAPP, Thomas F. Fintech reloaded - Traditional banks as digital ecosystems. Deutsche Bank Research. 2015.

DIVINO, José Ângelo; SILVA, Renan Said. Banking competition in the Brazilian economy. Nova Economia, v. 27, n.3, 2017.

ESTRADA, Manuel Martin Pino. A internet banking no Brasil, na América Latina e na Europa. Prismas: Direito, Políticas Públicas e Mundialização (substituída pela Revista de Direito Internacional), v. 2, n. 1, 2005.

FEDERAÇÃO BRASIlEIRA DE BANCOS, FEBRABAN. Pesquisa FEBRABAN de

Tecnologia Bancária 2018. 2019. Disponível em:
$<$ https://portal.febraban.org.br/pagina/3106/48/pt-br/pesquisa> Acesso em: 08 mai. 2019.

FUNDAÇÃO GETÚLIO VARGAS.FGV Dados: Conjuntura Econômica. Disponível em: $<$ https://portalibre.fgv.br/main.jsp?lumChannelId=402880811D8E34B9011D92C493F131B2 $>$ Acesso em: 14 fev. 2019.

GALBRAITH, John Kenneth; SANVICENTE, Antonio Zoratto. Moeda: de onde veio para onde foi. Cengage Learning Editores, 1997.

GOMES, M. C.; OLIVEIRA, S. V. W. B; MATIAS, A. B. Eficiência do setor bancário brasileiro no período de 2006 a 2013: bancos domésticos x bancos estrangeiros. Nova Economia, v. 27, n. 3, p. 641-670, 2017. DOI: http://dx.doi.org/10.1590/0103-6351/3057. 
GUJARATI, D.N.; PORTER, D.C. Econometria básica. 5. ed. Porto Alegre: AMGH Editora LTDA, 2011.

HORDONES, Cristiano Augusto Costa Melo. Poder de mercado e lucratividade: um estudo do setor bancário da América Latina. 2019. Dissertação de Mestrado.

HOTELLING, Harold. Stability in competition. In: The Collected Economics Articles of Harold Hotelling. Springer, New York, NY, 1929. p. 50-63.

LUCINDA, C. R. Competition in the Brazilian loan market: An empirical analysis. Estudos Econômicos, São Paulo, v. 40, p. 831-858, 2010.

MIA, Mohammad Abdul Hannan et al. E-Banking: Evolution, Status and Prospect. The Cost and Management, v. 35, n. 1, 2007.

NAKANE, M. I. A test of competition in Brazilian banking. Estudos Econômicos, n. 32, p. 203-224, 2002.

SAIDI, Normaizatul Akma et al. Determinants for adoption of e-banking among bank's customers. International Journal of Accounting, Finance and Business, v. 1, n. 2, p. 37 44, 2016.

SALOP, Steven C. Monopolistic competition with outside goods. 1979.

SHAIKH, Aijaz A.; KARJALUOTO, Heikki. Mobile banking adoption: A literature review. Telematics and informatics, v. 32, n. 1, p. 129-142, 2015.

SOMAINI, Paulo; EINAV, Liran. A model of market power in customer markets. The Journal of Industrial Economics, v. 61, n. 4, p. 938-986, 2013.

TABAK, B. M.; GOMES, G. M. R.; MEDEIROS JÚNIOR, M. D. S. The impact of market power at bank level in risk-taking: the Brazilian case. International Review of Financial Analysis, v. 40, p. 154-165, 2015.

VEIGA, Luiz Humberto Cavalcante; OLIVEIRA, Andre. Diferenciação Horizontal e Poder de Mercado: Os Efeitos do E-Banking sobre as Tarifas Bancárias. Revista Economia, 2006.

VON UNGERN-STERNBERG, Thomas. Monopolistic competiton on the pyramid. The Journal of Industrial Economics, p. 355-368, 1991.

WANG, Tao; WANG, Ruqu. A network-city model of spatial competition. Economics Letters, v. 170, p. 168-170, 2018.

ZAVOLOKINA, Liudmila; DOLATA, Mateusz; SCHWABE, Gerhard. FinTech-What's in a Name?. 2016. 